\title{
Prognostic value of serum uric acid level in patients with acute myocardial infarction
}

\author{
Ravella Keerthika Chowdary MD (DM Cardiology) ${ }^{1}$, Vamsi Krishna Kamana MD DM², Ashok Kumar KS MD³, \\ Seshagirirao Damara MD DM ${ }^{4}$, N Ramakumari MD DM ${ }^{5}$, Koneru Charitha MD $^{6}$
}

\begin{abstract}
RK Chowdary, VK Kamana, A Kumar, S Damara, N Ramakumari, K Charitha. Prognostic value of serum uric acid level in patients with acute myocardial infarction. Curr Res Cardiol 2016;3(3):63-66.
\end{abstract}

OBJECTIVES: To study the relationship between serum uric acid level and Killip classification in pateints with acute myocardial infarction (MI), and the use of serum uric acid levels as a marker of short-term mortality. METHODS: The present study involved 50 patients with acute MI and 50 controls. Serum uric acid level was measured on days 0,3 and 7 of MI, and compared with all clinical parameters and mortality in the enrolled subjects. RESULTS: There was a statistically significant higher serum uric acid concentration in patients with MI on the day of admission compared with controls. Patients with history of MI had higher serum uric acid levels. On

$\mathrm{C}$ oronary artery disease (CAD) is a worldwide health epidemic. Although age-specific events related to CAD have fallen dramatically in the past few decades, the overall prevalence has risen as populations age and patients survive the initial coronary or cardiovascular event. Globally, of those dying from cardiovascular diseases, $80 \%$ are in developing countries and not in the Western world. The Global Burden of Disease Study reported that in 1990 there were 5.2 million deaths from cardiovascular diseases in economically developed countries and 9.1 million deaths from the same causes in developing countries (1). The prevalence of CAD in India increased from 1\% in 1960 to $9.7 \%$ in 1995 in urban populations and, in rural populations, it has almost doubled in the past decade (2). Limitations in available resources to treat ST-elevation myocardial infarction (STEMI) in developing countries mandate major efforts on an international level to strengthen primary prevention programs (3).

Left ventricular dysfunction is the single most important predictor of mortality following STEMI (4,5). In 1967, Killip and Kimball (6) proposed a prognostic classification scheme on the basis of the presence and severity of rales detected in patients presenting with STEMI. Despite overall improvement in mortality rate in each class, compared with data observed during the original development of the classification scheme, the classification scheme remains useful today, as evidenced by data from large myocardial infarction (MI) trials involving STEMI patients (7). The Killip classification is a powerful independent predictor of all-cause mortality in patients with non-ST-elevation acute coronary syndromes (8).

There has been growing interest in the link between uric acid levels, xanthine oxidoreductase and cardiovascular disease. Previous studies have reported that a high concentration of uric acid is a strong marker of an unfavourable prognosis of moderate to severe heart failure and cardiovascular disease $(9,10)$. Uric acid levels may be elevated in heart failure and provide important prognostic information (11). A failing heart due to acute MI may cause tissue hypoperfusion and all days, serum uric acid levels were higher in patients who were in a higher Killip class. Two patients who died after three days of hospital stay had a serum uric acid level $>7.0 \mathrm{gm} / \mathrm{dL}$ and both were in Killip class IV.

CONCLUSIONS: Serum uric acid levels were higher in patients with acute MI compared with normal healthy individuals. In acute MI, patients with hyperuricemia had higher mortality. Serum uric acid levels correlated with Killip classification in patients with acute MI. Serum uric acid level can be used as a marker of short-term mortality in acute MI, and hyperuricemia may be an indicator of poor prognosis. Serum uric acid levels were elevated in acute MI patients with systemic hypertension and diabetes mellitus.

Key Words: Acute myocardial infarction; Serum uric acid

hypoxia, which trigger xanthine oxidase activation and oxidative stress $(12,13)$. Xanthine oxidase and oxidative stress, as reflected by uric acid levels, may form a vicious cycle that promotes severe heart failure $(9,12)$.

According to the Japanese Acute Coronary Syndrome Study (18), there was a close correlation between serum uric acid (SUA) concentration and Killip classification in patients with acute MI. Elevated SUA has been found to be closely associated with metabolic and other related syndromes (19-22).

Elevated SUA is also associated with hypertension and renal disease. It is present in $>75 \%$ of patients with malignant hypertension $(24,25)$. This elevation in these settings may be the result of decreased renal blood flow and resultant increased urate reabsorption, although this relationship is not completely understood $(24,26)$. Bickel et al (27) reported that a $1 \mathrm{mg} / \mathrm{dL}$ increase in SUA levels was associated with a $26 \%$ increase in mortality.

Siniša Car et al (28) found that higher SUA determined on admission was associated with higher in-hospital and 30-day mortality, and poorer long-term survival after acute MI. The Losartan Intervention For Endpoint reduction in hypertension (LIFE) study (31) demonstrated that lowering SUA concentrations by losartan was associated with a beneficial effect on cardiovascular outcome. The uric acid lowering effect of atorvastatin may have contributed to the decrease in cardiovascular mortality in the Greek Atorvastatin and Coronary Heart Disease Evaluation (GREACE) study (32).

In separate studies, Y1ldiz et al (29) and Nihat Kalay et al (30) found that SUA levels were higher in patients with slow coronary flow compared with controls.

We undertook the present study to note the levels of SUA in patients with acute MI to correlate SUA levels with Killip classification; to study the role of SUA as a marker of short-term mortality in acute MI; and to study the relationship between SUA and systemic hypertension and diabetes mellitus in acute MI.

${ }^{1}$ Department of Cardiology, NIMS, Punjagutta, Hyderabad; ${ }^{2}$ Interventional Cardiology, KMC, Manipal, Udupi, Karnataka; ${ }^{3}$ Gandhi Medical College,

Hyderabad, Telangana; ${ }^{4}$ IMS, Hyderabad, Telanagana; ${ }^{5}$ NIMS, Hyderabad, Telangana; ${ }^{6}$ MNR Medical College, Telangana, India

Correspondence: Dr Ravella Keerthika Chowdary, Department of Cardiology, NIMS, Punjagutta, Hyderabad, Telangana, India.

Telephone 9951609681, e-mail ravellamk@gmail.com 
TABLE 1

Clinical profile of cases and controls

\begin{tabular}{lccc}
\hline Parameter & Cases $(\mathbf{n}=\mathbf{5 0})$ & Controls $(\mathbf{n}=\mathbf{5 0})$ & $\mathbf{P}$ \\
\hline Age, years, mean $\pm \mathrm{SD}$ & $57.6 \pm 9.335$ & $58.6 \pm 7.027$ & $\mathrm{NS}$ \\
Sex, male/female, $\mathrm{n} / \mathrm{n}$ & $38 / 12$ & $35 / 15$ & $\mathrm{NS}$ \\
Systemic hypertension, \% & 52 & 50 & $\mathrm{NS}$ \\
Diabetes mellitus, \% & 68 & 64 & $\mathrm{NS}$ \\
Serum uric acid (day 1), mg/dL & 7.272 & 5.916 & $<0.01$ \\
\hline
\end{tabular}

NS Not statistically significant

TABLE 2

Serum uric acid levels in relation to Killip class on days 1, 3 and 5 following admission

\begin{tabular}{lcccc}
\hline Uric acid level & Killip class & Mean & ANOVA & P \\
\hline Day 1 & I & 5.51 & 84.190 & $<0.0001$ \\
& II & 8.05 & & \\
III & 11.18 & & \\
Day 3 & IV & 14.16 & & \\
& I & 5.27 & 7.488 & $<0.0001$ \\
& II & 6.75 & & \\
Day 5 & III & 7.76 & & \\
& IV & 8.05 & & \\
& I & 4.97 & 6.490 & \\
& II & 5.17 & & \\
\hline
\end{tabular}

\section{METHODS}

Study design

The present analysis was a prospective single-centre observational study conducted at the Gandhi Hospital (Hyderabad, India) between August 2011 and August 2013. Patients $>18$ years of age with STEMI or non-ST segment elevation MI (NSTEMI) on the basis of history, clinical examination, electrocardiographical changes and biochemical markers were included. Patients with a condition known to elevate SUA level (eg, chronic kidney disease, gout, hematological malignancy, hypothyroidism, hyperparathyroidism) were excluded. Patients taking drugs that increase SUA (eg, salicylates [>2 g/day], ethambutol, amiloride, bumetanide, chlorthalidone, cisplatin, cyclophosphamide, cyclosporine, ethacrynic acid, thiazide diuretics, furosemide, indapamide, isotretinoin, ketoconazole, levodopa, metolazone, pentamidine, phencyclidine, pyrazinamide, theophylline, vincristine or vitamin C were also excluded, as were chronic alcoholics.

\section{Patients}

Fifty patients with acute MI (STEMI and NSTEMI) who fulfilled inclusion/exclusion criteria were studied. Fifty age- and sex-matched controls were also evaluated for their baseline SUA level.

\section{Data analysis}

Data analysis was performed using SPSS (IBM Corporation, USA). Statistical analyses were performed using the $\chi^{2}$ test, $t$ test, Pearson correlation and Fischer's exact test; $\mathrm{P}<0.05$ was considerd to be statistically significant.

Ethics approval was obtained from the institutional ethics committee before commencemnt of the study. Patients enrolled provided informed consent and the protocol was approved by the institutional review committee.

\section{RESULTS}

Fifty patients with acute MI (STEMI and NSTEMI) and 50 age- and sex-matched healthy controls were studied. The profile of hypertensive and diabetic status and the mean SUA level on the day of admission of both the cases with acute MI and healthy controls are summarized in Table 1.

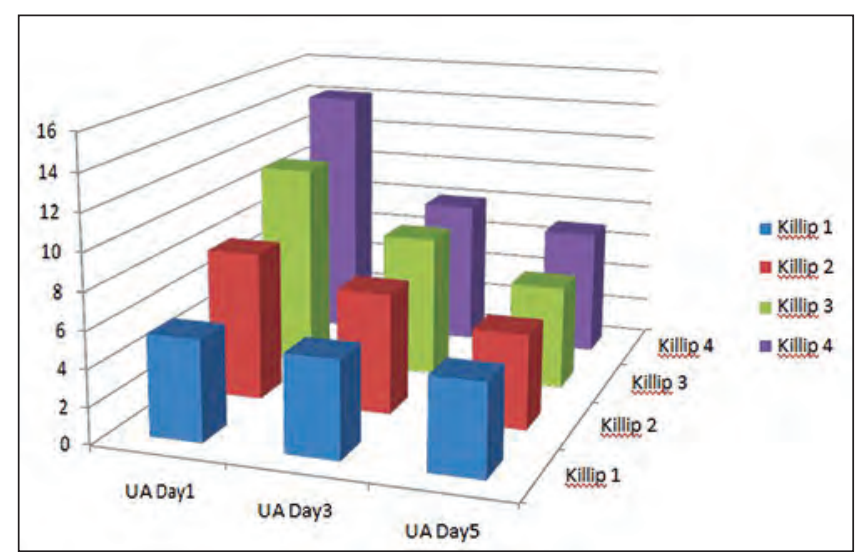

Figure 1) Serum uric acid (UA) levels in relation to Killip class on days 1, 3 and day 5 following admission

Patients with acute MI had statistically significant higher SUA levels on the day of admission compared with healthy controls $(\mathrm{P}<0.01)$. The majority $(60 \%)$ of the cases belonged to Killip class I, $22 \%$ to class II, $12 \%$ to class III and only $6 \%$ to class IV.

The mean SUA levels of male and female cases with MI on the day of admission was not significantly different $(t=0.759 ; \mathrm{P}=0.451)$. The mean SUA levels on day 3 and day 5 following admission was found to be higher in males compared with females with MI.

The mean SUA level was higher among cases who belonged to higher Killip class on the day of admission, and day 3 and day 5 following admission $(\mathrm{P}=0.001)$ Table 2.

Figure 1 depicts SUA levels in relation to Killip class on days 1, 3 and 5 following admission. On all days, SUA levels were higher in patients who were in higher Killip class $(\mathrm{P}<0.001)$. The SUA levels on the day of admission were significantly higher among patients in higher Killip class. Excluding two deaths by day 3, the SUA levels were found to be significantly higher in those belonging to higher Killip class on both days 3 and 5 . There was significant association between higher SUA level and patients who were hypertensive. SUA levels in patients with MI who were diabetic were also found to be significantly higher.

Table 3 summarizes the relationship between Killip class and mortality. Of the two patients who died, none was in Killip class I, II or III, and two were in Killip class IV at the time of admission. Patients who died were in higher class (class IV) at time of admission

Table 4 shows the association of SUA on day of admission with mortality. Of 50 patients, two dies during the seven-day follow-up. All patients who died had SUA levels $>7.0 \mathrm{mg} / \mathrm{dL}$. Thus, there appeared to be an association between SUA level and mortality.

\section{DISCUSSION}

We studied a total of 50 patients with acute MI, of whom 38 were male and 12 were female. Fifty age- and sex-matched controls were also evaluated for their baseline SUA level. There was no significant difference with regard to age, sex, status of systemic hypertension and diabetes mellitus in patients with acute MI and healthy controls.

The patients with acute MI had statistically significant higher SUA level on the day of admission compared with the healthy controls $(\mathrm{P}<0.0001)$.

We noted that there was a significant relationship between SUA level and mortality. All patients who died had SUA level $>7.0 \mathrm{mg} /$ $\mathrm{dL}(\mathrm{P}=0.041$ [Fisher's exact test]), as shown in Table 4. Thus, there was a significant association between SUA level and mortality. Siniša Car et al (28) found that higher SUA determined on admission was associated with higher in-hospital and 30-day mortality, and poorer long-term survival after acute MI. Thus, elevated SUA level may be associated with coranary artery disease. Nadkar and Jain (33) 
TABLE 3

Relationship between Killip class and mortality

\begin{tabular}{lccccc}
\hline & \multicolumn{4}{c}{ Killip class } & \\
\cline { 2 - 5 } Status & I & II & III & IV & Total \\
\hline Alive & 30 & 11 & 6 & 1 & 48 \\
Deceased & 0 & 0 & 0 & 2 & 2 \\
Total & 30 & 11 & 6 & 3 & 50 \\
\hline
\end{tabular}

Data presented as $n$

concluded that SUA levels were higher in patients with acute MI and were correlated with Killip class. In our study, the majority $(60 \%)$ of cases belonged to Killip class I, 22\% to Killip class II, 12\% to Killip class III and 6\% to Killip class IV.

In our study, there was significant relationship $(\mathrm{P}=0.042$ on day 1 , $\mathrm{P}=0.014$ on day 3 and $\mathrm{P}=0.001$ on day 5) between SUA level and patients who were known or found to be hypertensive on admission. Our study showed that hypertensive patients had more hyperuricemia. Kojima et al (18) noted that SUA concentration was significantly correlated with hypertension $(\mathrm{r}=0.301 ; \mathrm{P}=0.005)$.

There was a significant relation between SUA level and Killip class on day of admission (Table 2). In our study, patients in Killip class III and IV had higher levels of SUA compared with patients in Killip class I and II ( $\mathrm{P}=0.001)$. The mean SUA level was higher among those cases who belonged to higher Killip class; similar findings were noted by Kojima et al (18), Nadkar and Jain (33), and Killip and Kimball (6). However, Jularattanaporn et al (34) noted that there was no observed association between hyperuricemia and high TIMI risk scores or Killip class at first presentation or in-hospital adverse outcomes.

We also found a statistically significant positive correlation ( $r=0.840 ; \mathrm{P}=0.001)$ between CPK-MB on day of admission and Killip class: of 50 patients, two dies during the seven-day follow up. Of these, none were in Killip class I, II or III, and both were in Killip class IV at the time of admission. Thus, both patients who died were in higher class (Killip class IV) at time of admission.

In the present study, we found a close relationship between SUA concentration and Killip classification, suggestive of left ventricular failure. High SUA levels on admission were strongly associated with adverse clinical outcome in patients who had acute MI. Our study showed the value of SUA as a marker of short-term mortality in acute MI. Kojima et al (18) noted that hyperuricemia after acute MI was associated with the development of heart failure.

Nadkar and Jain (33) showed that SUA levels were higher in patients with acute MI and correlated with Killip class. A combination of Killip class and SUA level after acute MI is a good predictor of mortality after acute MI.

\section{CONCLUSIONS}

SUA levels were higher in patients with acute MI compared with normal healthy individuals. SUA levels are elevated in systemic hypertension and diabetes mellitus in patients with acute MI. In acute MI, patients with hyperuricemia had higher mortality. SUA levels correlated with Killip classification in acute MI. SUA can be used as a marker of short-term mortality in patients with acute MI. Hyperuricemia is an indicator of poor prognosis in acute MI.

ACKNOWLEDGEMENTS: The authors thank the Departments of Biochemistry and Cardiology at their institution for cooperation and help. RK Chowdary thanks her husband cardiologist for his support in completion of the manuscript.
TABLE 4

\begin{tabular}{|c|c|c|c|}
\hline Serum uric acid, $\mathrm{mg} / \mathrm{dL}$ & Died & Alive & Total \\
\hline$<4$ & 0 & 4 & 4 \\
\hline $4-7$ & 0 & 26 & 26 \\
\hline$>7$ & 2 & 18 & 20 \\
\hline Total & 2 & 48 & 50 \\
\hline
\end{tabular}

Data presented as $n$

\section{REFERENCES}

1. Murray CJ, Lopez AD. Mortality by cause for eight regions of the world: Global Burden of Disease Study. Lancet 1997;349:1269-76.

2. Gupta R, Mohan I, Narula J, et al. Trends in coronary heart disease epidemiology in India. Ann Global Health 2016;82:307-15.

3. Napoli C, Cacciatore F. Novel pathogenic insights in the primary prevention of cardiovascular disease. Prog Cardiovasc Dis 2009;51:503-23.

4. Frisch DR, Giedrimas E, Mohanavelu S, et al. Predicting irreversible left ventricular dysfunction after acute myocardial infarction. Am J Cardiol 2009;103:1206.

5. Reynolds HR, Hochman JS. Cardiogenic shock: Current concepts and improving outcomes. Circulation 2008;117:686.

6. Killip T, Kimball JT. Treatment of myocardial infarction in a coronary care unit. A two-year experience with 250 patients. Am J Cardiol 1967;20:457-63.

7. Montalescot G, Wiviott SD, Braunwald E, et al. Prasugrel compared with clopidogrel in patients undergoing percutaneous coronary intervention for ST-elevation myocardial infarction (TRITON-TIMI 38): Double-blind, randomised controlled trial. Lancet 2009;373:723.

8. Khot UN, Jia G, Moliterno DJ, et al. Prognostic importance of physical examination for heart failure in non-ST-elevation acute coronary syndromes. JAMA 2003;290:2174-218.

9. Anker SD, Doehner W, Rauchhaus M, et al. Uric acid and survival in chronic heart failure: Validation and application in metabolic, functional, and hemodynamic staging. Circulation 2003;107:1991-7.

10. Leyva F, Anker S, Swan JW, et al. Serum uric acid as an index of impaired oxidative metabolism in chronic heart failure. Eur Heart J 1997;18:858-65.

11. Longo F, Kasper M. Heart failure and Cor Pulmonale. Harrison's Principles of Internal Medicine, 18th edn. NewYork: McGraw Hill 2011:1902.

12. Hare JM, Johnson RJ. Uric acid predicts clinical outcomes in heart failure: Insights regarding the role of xanthine oxidase and uric acid in disease pathophysiology. Circulation 2003;107:1951-3.

13. Terada LS, Guidot DM, Leff JA, et al. Hypoxia injures endothelial cells by increasing endogenous xanthine oxidase activity. Proc Natl Acad Sci USA 1992;89:3362-6.

14. Kroll K, Bukowski TR, Schwartz LM, et al. Capillary endothelial transport of uric acid in guinea pig heart. Am J Physiol 1992,262:H420-H431.

15. Castelli P, Condemi AM, Brambillasca C, et al. Improvement of cardiac function by allopurinol in patients undergoing cardiac surgery. J Cardiovasc Pharmacol 1995;25:119-25.

16. Kogure K, Ishizaki M, Nemoto M. Evaluation of serum uric acid changes in different forms of hepatic vascular inflow occlusion in human liver surgeries. Life Sci 1999;64:305-13.

17. De Scheerder IK1, van de Kraay AM, Lamers JM, Koster JF, de Jong JW, Serruys PW. Myocardial malondialdehyde and uric acid release after short-lasting coronary occlusions during coronary angioplasty: Potential mechanisms for free radical generation. Am J Cardiol 1991;68:392-5.

18. Kojima S1, Sakamoto T, Ishihara M, et al. Prognostic usefulness of serum uric acid after acute myocardial infarction (Japanese Acute Coronary Syndrome Study). Am J Cardiol 2005;96:489-95.

19. Fam AG. Gout, diet, and the insulin resistance syndrome. J Rheumatol 2002;29:1350-5.

20. Laurence S, Sperling JI, Mechanick IJ, et al. The CardioMetabolic Health Alliance Working Toward a New Care Model for the Metabolic Syndrome. J Am Coll Cardiol 2015;66:1050-67. 
21. Kahn HS, Valdez R. Metabolic risks identified by the combination of enlarged waist and elevated triacylglycerol concentration. Am J Clin Nutr 2003;78:928-34.

22. Cornier MA, Dabelea D, Hernandez TL, et al. The metabolic syndrome. Endocr Rev 2008;29:777-822.

23. Dessein PH, Shipton EA, Stanwix AE, Joffe BI, Ramokgadi J. Beneficial effects of weight loss associated with moderate calorie/ carbohydrate restriction, and increased proportional intake of protein and unsaturated fat on serum urate and lipoprotein levels in gout: A pilot study. Ann Rheum Dis 2000;59:539-43.

24. Feig DI, Kang DH, Johnson RJ, et al. Uric acid and cardiovascular risk. N Engl J Med 2008;359:1811-21.

25. Cannon PJ, Stason WB, Demartini FE, Sommers SC, Laragh JH. Hyperuricemia in primary and renal hypertension. N Engl J Med 1966;275:457-64.

26. Anand NN, Padma V, Prasad A, et al. Serum uric acid in new and recent onset primary hypertension. J Pharm Bioall Sci 2015;7:54-8.

27. Bickel C, Rupprecht HJ, Blankenberg S, et al. Serum uric acid as an independent predictor of mortality in patients with angiographically proven coronary artery disease. Am J Cardiol 2002;89:12-7.

28. Siniša Car, Trkulja V, et al. Higher serum uric acid on admission is associated with higher short-term mortality and poorer long-term survival after myocardial infarction: Retrospective prognostic study. Croat Med J 2009;50:559-66.
29. Yildiz A, Yilmaz R, Demirbag R, Gur M, Bas MM, Erel O. Association of serum uric acid level and coronary blood flow. Coron Artery Dis 2007;18:607-13.

30. Nihat Kalay, Metin Aytekin, et al. The relationship between inflammation and slow coronary flow: Increased red cell distribution width ans serum uric acid levels. Arch Turk Soc Cardiol 2011;39:463-8.

31. Hoieggen A, Alderman MH, Kjeldsen SE, et al. The LIFE Study Group. The impact of serum uric acid on cardiovascular outcomes in the LIFE study. Kidney Int 2004;65:1041-9.

32. Athyros VG, Elisaf M, Papageorgiou AA, et al. The GREACE Study Collaborative Group. Effect of statins versus untreated dyslipidemia on serum uric acid levels in patients with coronary heart disease: A subgroup analysis of the GREek Atorvastatin and Coronary-heart-disease Evaluation (GREACE) study. Am J Kidney Dis 2004:43:589-99.

33. Nadkar MY, Jain VI. Serum uric acid in acute myocardial infarction. J Assoc Phys India 2008;56:759-62.

34. Jularattanaporn V, Krittayaphong R, Boonyasirinant $\mathrm{T}$, et al. Prevalence of hyperuricemia in Thai patients with acute coronary syndrome. Thai Heart J 2008;21:86-92. 